\title{
Non-Cooperative Collusion in Static and Dynamic Oligopolies
}

\author{
Stephen B. Wolf ${ }^{1,2}$ \\ ${ }^{1}$ Tufts University, Medford, USA \\ ${ }^{2}$ Pembroke College, Oxford, UK \\ Email: steviebwolf@gmail.com
}

Received April 17, 2013; revised May 17, 2013; accepted May 24, 2013

Copyright (C) 2013 Stephen B. Wolf. This is an open access article distributed under the Creative Commons Attribution License, which permits unrestricted use, distribution, and reproduction in any medium, provided the original work is properly cited. In accordance of the Creative Commons Attribution License all Copyrights (C) 2013 are reserved for SCIRP and the owner of the intellectual property Stephen B. Wolf. All Copyright (C) 2013 are guarded by law and by SCIRP as a guardian.

\begin{abstract}
This paper provides an analysis of collusion in oligopolies from a game-theoretic perspective. It first provides a basic survey of oligopoly models and then uses game theory to analyze non-cooperative or tacit collusion in these models, in a way that should be accessible to undergraduate economics students. In this way, the author characterizes the conditions under which collusive behavior might occur. Importantly, this paper draws its conclusions by using relatively basic methods with which those foreign to the subject should be able to understand.
\end{abstract}

Keywords: Game Theory; Oligopoly; Collusion

\section{Introduction}

Industrial organization is composed of a latticework of interactions between agents in situations of payoff interdependency, in which the optimal strategy for each agent depends on the actions of the others. In game theory, cooperation is said to be joint actions undertaken by agents in order to produce mutually beneficial outcomes; the goal of industrial economics is to examine the detailed institutional framework of industries as well as the actions of the agents and firms that constitute them, and it will be highly informative to discuss the conditions by which cooperative behavior occurs between self-regarding rational actors.

The purpose of this paper is to examine the potential for non-cooperative collusive behavior in oligopoly markets, also known as "tacit collusion", seeking specifically to identify if and when cooperative equilibria can occur between otherwise competitive forces. It is important to note the limited scope of this paper, which does not test its conclusions by using available data; as such this paper is best read as a survey and examination of the contemporary literature. Section 2 will begin by explaining noncooperative games, emphasizing that complete independence of each agent creates the potential for highly competitive behavior. Section 3 will then discuss interactions in static oligopolies, focusing on the Bertrand model in particular and questioning the assumption of a one-shot game. Section 4 will examine dynamic oligopolies, emphasizing foresight as a major factor in the maintenance of a collusive equilibrium. Section 5 will summarize the previous sections and discuss their conclusions.

\section{Non-Cooperative Agents}

For any sort of game-theoretic interaction, equilibrium must not only arise as a result of the actions chosen by agents but also must be a sustainable outcome if the game were to be played repeatedly. In this paper, we restrict our scope to non-cooperative games, or those in which agents are not already bound by explicit agreement or contract to act cooperatively and cannot make binding commitments to each other; thus, strategies cannot be jointly coordinated or arranged by multiple agents. In such a system, it is the perfectly discrete nature of agents, their payoffs, their actions, and available information that may prevent cooperative outcomes from being reached. In other words, even though agents may have the same constraints and may be seeking fulfillment of the same objective, there exists potential for competitive behavior and a zero-sum outcome ${ }^{1}$, simply because

\footnotetext{
${ }^{1}$ A zero-sum game is one in which a single agent wins and the others lose without question.
} 
each agent is a separate and distinct actor who assumes his competitors will act according only to their own self-interest. Thus, in this paper I will refer to cooperative and collusive outcomes interchangeably, as I ignore the possibility of contractual obligations.

Nonetheless, the potential for competitive behavior does not preclude non-coordinated attainment of a cooperative equilibrium that is mutually more beneficial. According to Ray Rees [1], collusive behavior between cooperative agents requires a process of communication or exchange of information by which coordination can occur as well as some explicit mechanism of punishing those who fail to uphold the agreement, and in the absence of such a mechanism reinforcing a cooperative outcome, any communication or words coordination amongst non-cooperative agents will be considered nothing more than "cheap talk". Thus, collusive equilibria in non-cooperative games must be sustained purely by the self-interests of those agents involved, who are assumed to act only in order to maximize their own utility functions.

\section{Cooperation in Static Oligopolies}

Non-cooperative interactions in markets of imperfect competition are represented at the most fundamental level by the classic models of static oligopoly. Cleanly put by Church \& Ware [2], these models are "essentially timeless" and act as a "simple forum to introduce the concepts of payoff interdependency and strategic interaction" ([2], p. 232); they demonstrate almost too well how Nash equilibria-a strategy set in which each agent has followed his or her best response strategy, and no one can improve his or her payoff by choosing a different individual action — can be below the optimal total payoff that could have been achieved through cooperation. However, as we shall see, these models are severely limited in explanatory power.

The two basic models are the Cournot and Bertrand oligopolies; in both, the game consists of simultaneous play during a single period under perfect information, in which two agents (there can be multiple, but we will assume only two agents engage in the static market) compete by choosing a production strategy of homogeneous goods to maximize their own payoffs given perceptions about how rivals will act. In the Bertrand model, the firms choose the prices of the goods they supply, while in the Cournot model they set the levels of quantity at which they will produce and take whatever price allowed by the demand curve. For the sake of conciseness, we will only examine the Bertrand model, because it makes a cleaner statement about the limits of cooperative behavior in a single period.

The simplest variation of the Bertrand models sees each firm setting the price at which it will sell the goods it produces, and producing the quantity of goods demanded by consumers at that price. The strategy set available to each firm consists of setting some price $p_{i}^{B}$, for $i=1$, 2, that has properties of

$$
p^{C} \leq p_{i}^{B} \leq p^{M}
$$

where $p^{C}$ is the price level at a competitive equilibrium and $p^{M}$ is the monopoly price level. For firms without fixed costs, $p^{C}$ is equal to marginal cost and generates zero profit. Firms will not set $p_{i}^{B}$ below $p^{C}$ because it would imply a loss on every unit sold, nor above $p^{M}$ as it is price at which profit is maximized. Throughout this paper, we will assume that barriers to entry ${ }^{2}$ are sufficiently high such that even if both firms were to set price equal to $p^{M}$, profits would not be enough to induce other agents to enter the industry; thus, $p^{M}$ truly is the maximum level at which a firm would set its price. In practice, such high barriers to entry are quite rare in most markets; however, we will maintain this assumption throughout this paper because it suits a game-theoretic approach. Gilbert [4] provides an in-depth discussion of dynamic markets that incorporates barriers to entry.

In this variation of the Bertrand model, there is no product differentiation, spatial or temporal factors affecting consumer preferences, asymmetric information among consumers, nor capacity constraints on firms' production; as a result, whichever firm sells the its product at a lower price will supply the entire market, leaving the other firm with zero sales (and a profit less than or equal to zero, depending on whether production has already begun and whether marginal cost is non-refundable). The game becomes a slightly more complex version of the Prisoner's Dilemma and is a zero-sum game for all price combinations where $p_{1}^{B} \neq p_{2}^{B}$. Firm 1 knows that, for any $p_{2}^{B}$ chosen by firm 2, it can undercut its competitor by setting $p_{1}^{B}<p_{2}^{B}$ and steal firm 2's entire profits, something that firm 2 is quite aware of. Because at all price combinations above $p^{C}$ there is an incentive for either firm to increase its profits and undercut its competitor, the Nash equilibrium of the interaction occurs at

$$
p_{1}^{B}=p_{2}^{B}=p^{C},
$$

in which no agent has a profitably deviating strategy, resulting in a total profit equal to zero. Thus, according to the Bertrand model and the Nash equilibrium reached through game-theoretic analysis, price competition between two agents in static game results in a complete destruction of profits and market equilibrium equal to

\footnotetext{
${ }^{2}$ The definitions of "barriers to entry" are numerous and varied, making a common understanding of the concept difficult, though not impossible For our purposes, we will define them as any market condition that may explain a difference in profitability between incumbent firms and prospective entrants. For more information on barriers to entry, see Cabral [3].
} 
that of a perfectly competitive market, despite imperfect competition. On the surface, this equilibrium is extremely different from that of the Cournot model, where firms exercise market power as a negative function of the elasticity of demand and the number of firms in the market, resulting in an equilibrium price and quantity above and below, respectively, that of the competitive equilibrium $^{3}$ ([2], p. 243; [1], p. 23). However, the outcomes of the Cournot and Bertrand models are thematically interchangeable; regardless of whether price or quantity is chosen as a variable, static markets under imperfect competition will generate an equilibrium total profit well below that reached in a monopoly.

Without prior knowledge of whether the game will be repeated, neither firm engages in collusive behavior because both seek to maximize profits in the current period. However, these static models are highly questionable both in their implications and assumptions. The Bertrand model, it could be said, implies that agents seek to beat their competitors at all costs, even if it means the complete destruction of the profitability of the entire industry; it therefore assumes that agent utility is a function of profit alone. If the Bertrand model were to be examined using utility functions that in part depended on the strength and profitability of the industry as a whole, would that allow for the possibility of a cooperative equilibrium between non-cooperative agents? This matter requires further investigation. Yet the most blatant criticism of the static oligopoly models is that the assumption of a one-shot game interaction is extremely unrealistic, no matter the industry; therefore, to assess cooperative behavior in a more useful way, we much analyze these markets in a dynamic context, with the present knowledge that repeated games will occur in the future.

\section{Tacit Collusion in Dynamic Oligopoly}

In considering dynamic oligopoly, we allow for the multiple repetitions of the game-theoretic interaction in question; agents are aware of this repetition, so payoffs in the current period take into account profits from future periods. To begin, we forgo the Bertrand assumption that the firm with the lowest price will supply the entire market, and instead move towards a Cournot equilibrium in which price is below monopoly level but above marginal cost. Yet rather than focusing on either price or output as the competitive variable, let us consider them as two sides of the same coin; joint restriction of output and growth of prices will increase total profit while an indi-

\footnotetext{
${ }^{3}$ The reason for this is that, in the Cournot model, individual firms set quantities of output given perceptions that its rival will sell a fixed quantity. The demand curve faced by each firm is much less elastic than those in the Bertrand model, where a firm can win full share of the market by undercutting its competitors even by a miniscule amount making for an extremely elastic demand. (Church \& Ware [2], p. 270).
}

vidual firm lowering prices and increasing output above the monopoly level will steal market share from its competitors - though not necessarily reducing their sales to zero.

With all this in mind, we can now examine tacit collusion in and of itself as the occurrence of cooperative actions in repeated non-cooperative games. Consider an oligopoly market in which each firm has set its price equal to the monopoly price level and restricted output to its share of the monopoly quantity. Industry profit is maximized and the market is an optimum collusive equilibrium; however, any one firm could increase its individual profit at the cost of total profit in the next period by setting price below the collusive level and increasing output according to the demand curve, maximizing individual profits given the price and output choices of its competitors. This threat of competitive behavior is always present in collusive equilibrium. However, each firm is aware that any deviation from the collusive outcome will, depending on the ability of other firms to detect and swiftly respond, set off a price war that will generate heavy losses in future periods. Thus, for each individual firm, the decision to defect from the collusive equilibrium in a given period depends entirely on the tradeoff between current and future profit.

There are several factors identified by the literature that are critical to evaluating this tradeoff. First, a potential defector must be able to evaluate the profits in the long term associated with maintaining a cooperative equilibrium. Assuming market demand and cost conditions will be roughly the same across periods, firms will earn a collusive profit $\pi^{M}$ in every period in which all firms maintain the monopoly price and total output. However, it is a fundamental theme in economics that the value of a given income in the current period is much greater than the value of the same amount in successive periods; the present value of expected future profits must reflect this by discounting future cash flows. This discount rate-represented by $r$-will often reflect the cost of capital per period for the firm. Firms with high levels of capital depreciation and thus larger capital costs will more heavily discount the present value of future income; these firms will be less likely to maintain a collusive equilibrium. Furthermore, the size of the discount rate $r$ is significant in determining not only the present value of maintaining a collusive equilibrium in future periods, but also how costly the future losses of profit caused by punishment will be relative to the immediate gains obtainable by defecting.

Next, the immediate payoff associated with defecting from the collusive equilibrium is the increased profit level $\pi^{R}$ obtained by the firm that increases output and decreases price while other agents maintain monopoly level price and output. The size of this augmented payoff 
depends "partly on cost, demand, and capacity parameters and partly on the length of time for which a higher profit... can be earned before retaliation by the other firms takes place” ([1], p. 31). Rees further comments that the short term gain to breaking a collusive equilibrium would be virtually nonexistent if production were constrained by a maximum rate of capacity output given technology and if the output of each firm under the collusive agreement were close to capacity; conversely, if there were an excess capacity above the collusive output level and the monopoly price is sufficiently greater than marginal cost, then it would be both feasible and profitable for a firm to defect from the collusive agreement. Furthermore, the ability of other firms to respond punitively towards the defector and to do so with alacrity also affects the immediate payoff of defecting. According to Church \& Ware [2], a low likelihood that non-defecting firms will detect price cuts and increased outputs as well as a great length of time (i.e. a high number of periods) required for these firms to implement punitive strategies will weaken the sustainability of a collusive equilibrium.

The final critical factor in the tradeoff facing a potential defector is the evaluation of the punitive consequences of breaking collusion. One way to model these punitive actions is explained by Martin [5] citing James Friedman's trigger strategy. The trigger strategy consists of two central features: 1) each firm produces output to its share of the monopoly quantity - with price and thus total profit maximized at the monopoly level—and will continue to do so in the following period so long as all other firms cooperated in the previous period by also maintaining monopoly price and quantity; and 2) if in any period the price offered by any firm is lower than the monopoly level, all firms revert to their Nash equilibrium price and output combinations-either permanently or until such time as the short-term profit increase from defecting is offset by the profit lost over multiple periods by forgoing cooperative outcome. However, one limitation to this reversion to the Nash equilibrium as a viable form of punishment is that it may not be very severe, since in this case the Nash equilibrium is a Cournot quantity that is below competitive and above its share of the monopoly level, implying only "a moderate loss of profit relative to the collusive agreement” ([1], p. 32). A more sever alternative is known the minimax punishment. For each firm in the market, we can define a production and price strategy that is the firm's best response given actions of all other agents in the market. By identifying the actions that generate the smallest best response profit, or the minimax profit, for the firm in question and then pursuing these actions, the non-defectors can punish the defecting firm more heavily than simply reverting to the Nash equilibrium.

Regardless of the method of punishment implemented, the trigger strategy appears in practice in the form of any conditions that lend credibility to the threat of punitive actions, as well as increase their ability to generate heavy future losses for the defector ${ }^{4}$. Frequent interactions between firms will ensure that they are aware of each other's price and output choices in a given period and thus can detect any attempts to undercut cooperation right after they happen. A high degree of product homogeneity will prevent firms from maintaining price differences that might have been enabled by product differentiation; thus, a defector receives little to no protection from punishment, as it cannot sustain a price above the punitive level forced by its competitors. Price matching guarantees provide credibility to threats of punishment, ensuring that any competitive behavior will be met with a swift and cutthroat price war. Thus, these competitive qualities provide a built-in trigger strategy and actually increase the likelihood of collusive behavior.

The factors and conditions influencing the sustainability of a collusive equilibrium are combined in what is known as the Folk Theorem ([1,7]). Using $\pi^{S}$ to denote the minimax punishment profit, the $i$ th firm,

$i=1,2, \cdots, k$, will not defect if

$$
\left(\pi_{i}^{R}-\pi_{i}^{M}\right) \leq\left(\pi_{i}^{M}-\pi_{i}^{S}\right) / r .
$$

In words, if for each firm the immediate profit gain from defecting from the collusive equilibrium is less than the present discounted value of future profit losses resulting from minimax punishment during an infinite number of periods, then the collusive equilibrium will likely be sustained.

\section{Conclusion and Summary}

Using the separate components discussed, we can make several statements as to the conditions under which tacit collusion between non-cooperative agents is likely to occur, as well as concerning the strength and sustainability of these collusive equilibria. In a one-shot game, agents are unlikely to collude because it will be always one's interest to break collusion; this conclusion can also be applied to any market with sufficiently narrow time horizons such that firms look no further than the single upcoming period. In dynamic oligopolies, collusion is likely to be sustained when the present value of future losses exceeds the immediate payoff associated with defection from a cooperative equilibrium. While there are a number of factors that help define this tradeoff such as capital costs, firm interactions, capacity parameters, and severity of minimax punishments, it is only when we consider foresight and the role of future expectations

\footnotetext{
${ }^{4} \mathrm{An}$ alternative analysis to the trigger strategy is reputation maintenance in which firms cooperate in order to cultivate a reputation for cooperation. For more information, see Bowles \& Gintis [6].
} 
when these issues appear. The essence of cooperative behavior lies in the ability to interpret future strategies and possible events in the current period.

\section{REFERENCES}

[1] R. Rees, “Tacit Collusion,” Oxford Review of Economic Policy, Vol. 9, No. 2, 1993, pp. 27-40. http://dx.doi.org/10.1093/oxrep/9.2.27

[2] J. Church and R. Ware, "Industrial Organization: A Strategic Approach,” Irwin McGraw Hill, London, 2000.

[3] L. Cabral, "Barriers to Entry”, In: S. N. Durlauf and L. E. Blume, Eds., The New Palgrave Dictionary of Economics, in New Palgrave Dictionary of Economics, 2nd Edition,
Palgrave Macmillan, 2008.

[4] R. Gilbert, "The Role of Potential Competition in Industrial Organization,” Journal of Economic Perspectives, Vol. 3, No. 3, 1989, pp. 107-127. http://www.jstor.org/stable/1942764

[5] S. Martin, "Industrial Organization in Context," Oxford UP, Oxford, 2010.

[6] S. Bowles and H. Gintis, “Cooperation,” In: S. N. Durlauf and L. E. Blume, Eds., New Palgrave Dictionary of Economics, 2nd Edition, Palgrave Macmillan, 2008.

[7] G. Bitsakakis, "Static and Dynamic Oligopoly," Class Lecture, Pembroke College, Oxford University, 1-6 May 2012. 